\title{
A Method for Calculating the Fire Resistance of Exposed Timber Decks
}

\author{
MARC L. JANSSENS 1 \\ American Forest \& Paper Association \\ 1111 Nineteenth Street NW, Suite 800 \\ Washington, DC 20036 USA
}

\begin{abstract}
A simple calculation method was developed to estimate the fire resistance of timber decks. The method consists of equations to determine the time to thermal penetration and the time to structural failure. The former is based on a recommendation in Eurocode 5, Part 1.2. The latter resulted from a transformed section analysis for a range of load ratios and plank thicknesses; assuming a constant charring rate, experimentally validated temperature profiles, safety factors commonly used in the U.S., and temperature effects on stiffness reported in the literature. The calculation method is in reasonable agreement with experimental data obtained in the 1960's.
\end{abstract}

KEYWORDS: calculation methods, decks, fire resistance, wood

\section{NOTATION}

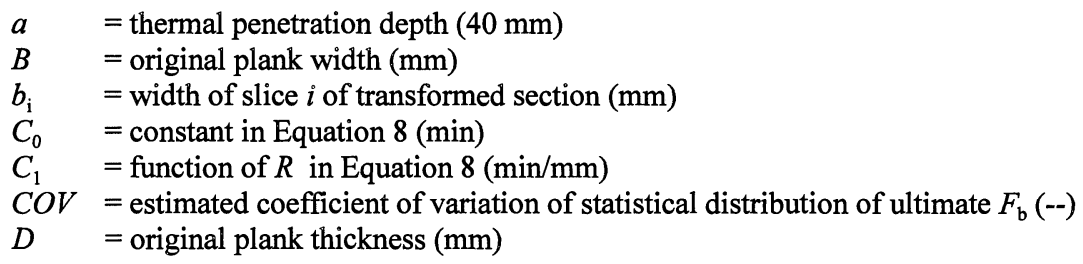

1 Current address of the author: Southwest Research Institute, 6220 Culebra Road, San Antonio, Texas 78238, USA 
$d \quad=$ thickness of remaining section $(\mathrm{mm})$

$d_{\mathrm{i}} \quad=$ thickness of slice $i$ of transformed section $(\mathrm{mm})$

$E \quad=$ modulus of elasticity $(\mathrm{GPa})$

$F_{\mathrm{b}} \quad=$ bending strength $(\mathrm{MPa})$

$k_{\mathrm{b}} \quad=$ ratio of design $F_{\mathrm{b}}$ to average ultimate $F_{\mathrm{b}}(--)$

$k_{\mathrm{b}}^{\prime} \quad=$ ratio of design $F_{\mathrm{b}}$ to fifth percentile ultimate $F_{\mathrm{b}}(--)$

$R \quad=$ ratio of applied to design load (--)

$S(t) \quad=$ transformed section modulus after $t$ minutes of fire exposure $\left(\mathrm{mm}^{3}\right)$

$T \quad=$ temperature $\left({ }^{\circ} \mathrm{C}\right)$

$T_{\mathrm{a}} \quad=$ ambient and initial temperature $\left(20^{\circ} \mathrm{C}\right)$

$T_{\mathrm{c}} \quad=$ temperature at the char front $\left(300^{\circ} \mathrm{C}\right)$

$T_{\mathrm{i}} \quad=$ temperature of slice $i$ of transformed section $\left({ }^{\circ} \mathrm{C}\right)$

$x \quad=$ distance from the char front $(\mathrm{mm})$

$t_{\mathrm{sf}} \quad=$ time to structural failure (min)

$t_{\mathrm{tf}} \quad=$ time to thermal failure (min)

\section{Greek}

$\beta \quad=$ charring rate $(\mathrm{mm} / \mathrm{min})$

$\beta_{0} \quad=$ design charring rate $(\mathrm{mm} / \mathrm{min})$

$\delta=$ additional char depth for effective cross-section method (mm)

$\xi \quad=$ reduction coefficient to account for increased charring at the joints (--)

$\rho_{0} \quad=$ oven dry density $\left(\mathrm{kg} / \mathrm{m}^{3}\right)$

\section{INTRODUCTION}

Heavy timber construction has long been recognized for its ability to maintain structural integrity while exposed to fire. Exposed wood structural members are popular with architects and designers of modern buildings because they have a pleasing appearance, are economical and easy to work with while providing the necessary fire endurance. The superior fire performance of heavy timbers can be attributed to the charring effect. As wood members are exposed to fire, an insulating char layer is formed that protects the core of the section. Thus, members can be designed so that a sufficient cross section of wood remains to sustain the loads for the required duration of fire exposure. A standard fire exposure is used for design purposes. In North America this exposure is described in the standard fire endurance test ASTM E 119 [1]. Many other countries use a comparable test exposure based on ISO 834 [2]. In spite of the differences between standard fire endurance tests, experimental charring rates measured in various parts of the world seem to be consistent. This justifies the use of such data for design, regardless of the origin.

The design method for fire-resistive exposed timber beams and columns used in North America is based on research that T.T. Lie conducted at the National Research Council of Canada in the 1970's [3]. The method was first recognized by the U.S. model building codes in 1984 as a National Evaluation Report [4]. In subsequent years, the method was adopted by the three model code organizations, allowing architects and builders to include fire-rated heavy timber members in their projects without conducting expensive standard fire resistance tests. Similar design methods for beams and columns exist in many other countries. The most recently developed procedures for the fire design of exposed timbers are described in Eurocode 5: 
Design of timber structures - Part 1.2: General rules - Structural fire design. This document was published by the European Commission for Standardization (CEN) in November 1994 as a European prestandard (ENV 1995-1.2:1994) [5].

In the U.S. no design equations have been developed for exposed timber decks. The aforementioned Eurocode provides only partial design guidelines. Timber decks consist of planks that are at least $38 \mathrm{~mm}$ thick ( 2 inches nominal). The planks span the distance between supporting beams, and can be arranged in different ways depending on the available lengths [6]. The planks are typically $140 \mathrm{~mm}$ wide (6 inches nominal). Usually, a single or double tongueand-groove method is used to connect adjoining planks, but splines or butted joints are also common. Based on the experience with beams and columns, it is expected that a simple calculation method for the fire endurance of timber decks would significantly increase the application and use of this type of fire-resistive construction. The objective of this paper is to develop and validate a calculation method for the fire resistance of exposed timber decks, that is comparable to the design equations currently accepted in the U.S. for the fire design of exposed wood beams and columns.

\section{CALCULATING FIRE RESISTANCE OF DECKS}

In order to meet the requirements for a given fire resistance rating, a floor deck needs to maintain its separating function and load carrying capacity for the specified duration of exposure to standard fire conditions. The former means that the temperature rise on the unexposed side of the floor deck must not exceed critical values of $140^{\circ} \mathrm{C}$ on average over the entire surface area, or $180^{\circ} \mathrm{C}$ at a single location [1][2]. The latter means that the deck shall carry the specified load, and shall not deflect beyond an acceptable service limit. The two aspects of the fire design of decks are discussed in detail below.

\section{Thermal Separation}

A method for calculating the thermal penetration through decks is given in Eurocode 5, Part 1.2 [5]. The time to termination of the separating function depends on the thickness of the deck, and can be estimated from Equation (C.1) in the Eurocode

$$
t_{t f}=\xi \frac{D}{\beta_{0}}
$$

where $\mathrm{t}_{\mathrm{tf}} \quad=$ time to thermal failure $(\mathrm{min})$;

$\xi \quad=$ reduction coefficient to account for increased charring at the joints (--);

$D \quad=$ thickness of the decking $(\mathrm{mm})$; and

$\beta_{0} \quad=$ design charring rate $(\mathrm{mm} / \mathrm{min})$.

$\xi=0.2$ for butted joints, $\xi=0.4$ for single tongue and groove or spline, and $\xi=0.6$ for double tongue and groove. There are minimum dimensions for the splines or tongues, which presumably, are derived from the test data that served as a basis for these values. The design 
charring rate values, $\beta_{0}$, for members with a minimum dimension of $35 \mathrm{~mm}$ are listed below.

- Solid sawn softwoods with $\rho_{0} \geq 290 \mathrm{~kg} / \mathrm{m}^{3} \ldots \ldots \ldots \ldots \beta_{0}=0.8 \mathrm{~mm} / \mathrm{min}$

- Glued laminated softwoods with $\rho_{0} \geq 290 \mathrm{~kg} / \mathrm{m}^{3} \ldots \ldots \ldots \beta_{0}=0.7 \mathrm{~mm} / \mathrm{min}$

- Hardwoods with $\rho_{0} \geq 450 \mathrm{~kg} / \mathrm{m}^{3} \ldots \ldots \ldots \ldots \ldots \ldots \beta_{0}=0.5 \mathrm{~mm} / \mathrm{min}$

- Hardwoods with $\rho_{0} \geq 290 \mathrm{~kg} / \mathrm{m}^{3} \ldots \ldots \ldots \ldots \ldots \ldots \beta_{0}=0.7 \mathrm{~mm} / \mathrm{min}$

Interpolation is permitted for densities in between the $290 \mathrm{~kg} / \mathrm{m}^{3}$ and $450 \mathrm{~kg} / \mathrm{m}^{3}$ limits. If the minimum density requirements are not fulfilled, $\beta_{0}$ is estimated based on the assumption that it is proportional to the inverse of the square root of $\rho_{0}$. The design charring rate values, $\beta_{0}$, are higher than experimental charring rate values, $\beta$, to account for the higher rate of charring at arisses. If there is a wood subfloor and/or floor on top of the deck, the thickness of the floor and subfloor can be added to that of the deck planks to calculate $t_{\mathrm{tf}}$ according to Equation (1).

\section{Structural Performance}

The procedure to determine the time to structural failure of deck planks is similar to that for beams. Structural failure of a beam is assumed to occur when the following critical condition is reached

$$
\frac{S\left(t_{s f}\right)}{S(0)}=R k_{b}
$$

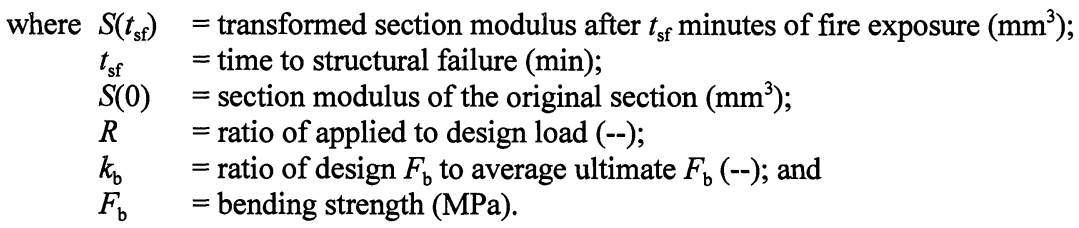

The "design" load results in a maximum bending stress equal to the design stress, $F_{\mathrm{b}}$, for a single member. The factor $k_{\mathrm{b}}$ is the ratio of design bending strength to average ultimate bending strength, and can be calculated from

$$
k_{b}=k_{b}^{\prime}(1-1.645 C O V)
$$

where $k_{\mathrm{b}}^{\prime} \quad=$ ratio of design $F_{\mathrm{b}}$ to fifth percentile ultimate $F_{\mathrm{b}}$; and

$\mathrm{COV}=$ estimated coefficient of variation of statistical distribution of ultimate $F_{\mathrm{b}}(--)$.

With $k_{\mathrm{b}}^{\prime}=0.476$ for softwood and $k_{\mathrm{b}}^{\prime}=0.435$ for hardwood [7], and $C O V=0.25$ for solid sawn lumber and $C O V=0.11$ for glulam [8], values for $k_{\mathrm{b}}$ are obtained as shown in Table 1. 
TABLE 1. Values for $k_{\mathrm{b}}$

\begin{tabular}{ccccc}
\hline & \multicolumn{2}{c}{ Softwood } & \multicolumn{2}{c}{ Hardwood } \\
\cline { 2 - 5 } & Solid Sawn & Glulam & Solid Sawn & Glulam \\
\cline { 2 - 5 }$k_{\mathrm{b}}$ & 0.280 & 0.400 & 0.256 & 0.356 \\
\hline
\end{tabular}

$S(t)$ is the section modulus of the transformed section that remains after $t$ minutes of fire exposure. The section has to be transformed to account for the (partial) heating of the remaining section. This technique is common for composite beams [9], and its application for deck planks exposed to fire is described below.

Prior to the start of fire exposure, the entire section is at ambient temperature as shown in Figure 1a. The section modulus is equal to its initial value. Shortly after the start of exposure, charring is initiated at the bottom edge directly exposed to the fire. The temperature distribution quickly approximates a one-dimensional profile as shown in Figure 1b. As long as the thickness of the remaining section, $d$, is equal to or greater than $40 \mathrm{~mm}$, this profile for $x \leq 40 \mathrm{~mm}$ can be approximated as [10]

$$
T(x)=T_{a}+\left[T_{c}-T_{a}\right]\left[1-\frac{x}{a}\right]^{2} \quad(\text { for } d \geq a \text { and } x \leq a)
$$

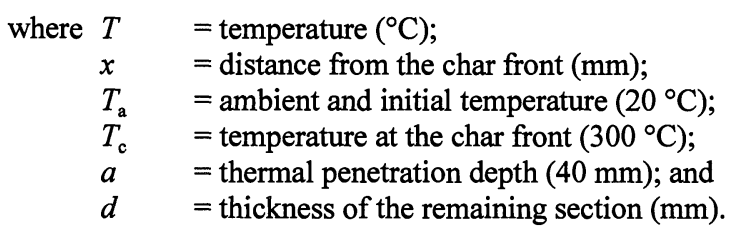

The validity of Equation (4) was confirmed by independent test data obtained in the U.S. [11]. If the thickness of the remaining plank section is less than $40 \mathrm{~mm}$, the temperature profile is affected by the boundary conditions on the unexposed side as shown in Figure 1c. Conservatively assuming that there are no heat losses through the top plane, the following equation from the final draft of Eurocode 5, Part 1.2 [10] can be used to estimate the temperature distribution:

$$
T(x)=T_{a}+\left[T_{c}-T_{a}\right]\left[1-2 \frac{x}{a}+2 \frac{x^{2}}{a d}\right] \quad(\text { for } d<a \text { and } x \leq d)
$$

The time to structural failure is determined in an iterative manner by solving Equation (2) using a bisection technique. Upper and lower bounds are determined of a range that contains the solution. Suitable lower and upper limits are 0 and $D / \beta_{0}$ respectively. To determine the transformed section modulus after an estimated $t$ minutes of fire exposure, the remaining thickness is first calculated from 


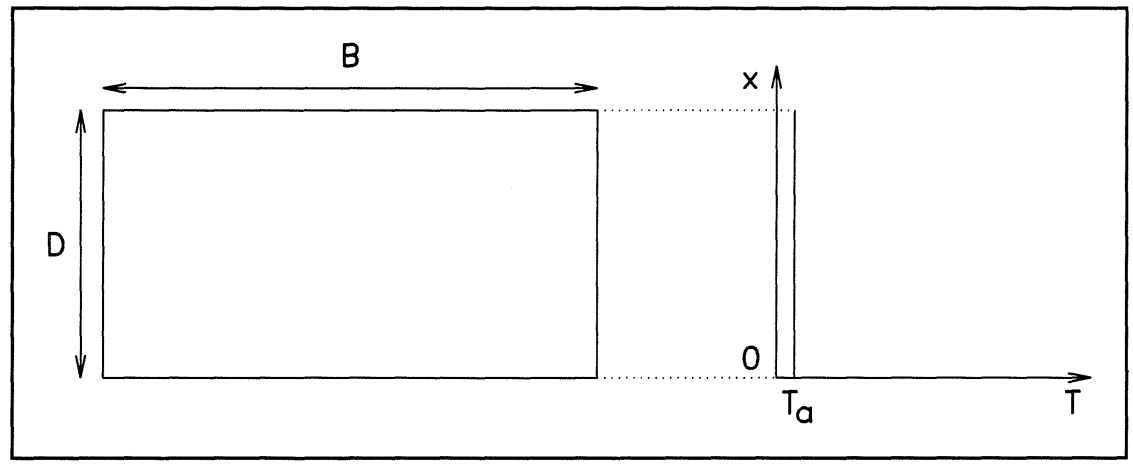

FIGURE 1a. Plank section before fire exposure

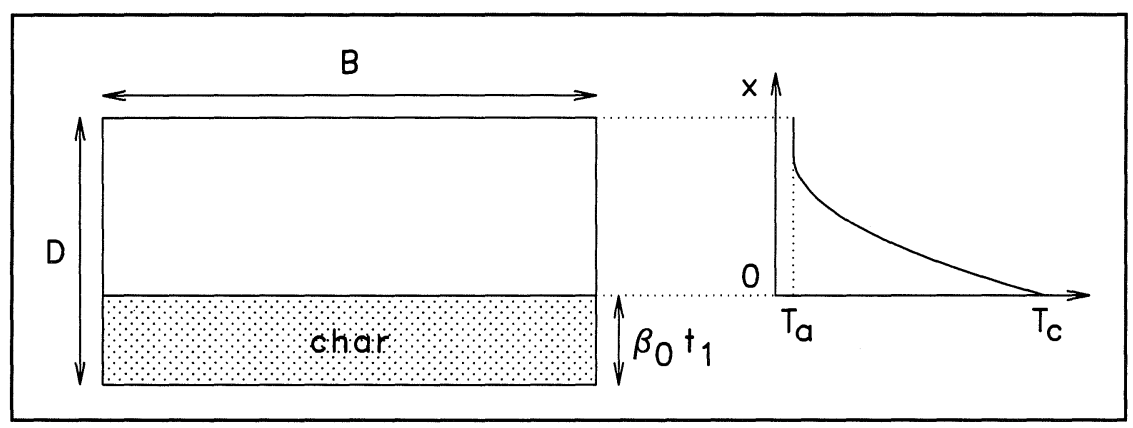

FIGURE 1b. Plank section after $t_{1}$ min of fire exposure $\left(d=D-\beta_{0} t_{1} \geq 40 \mathrm{~mm}\right)$

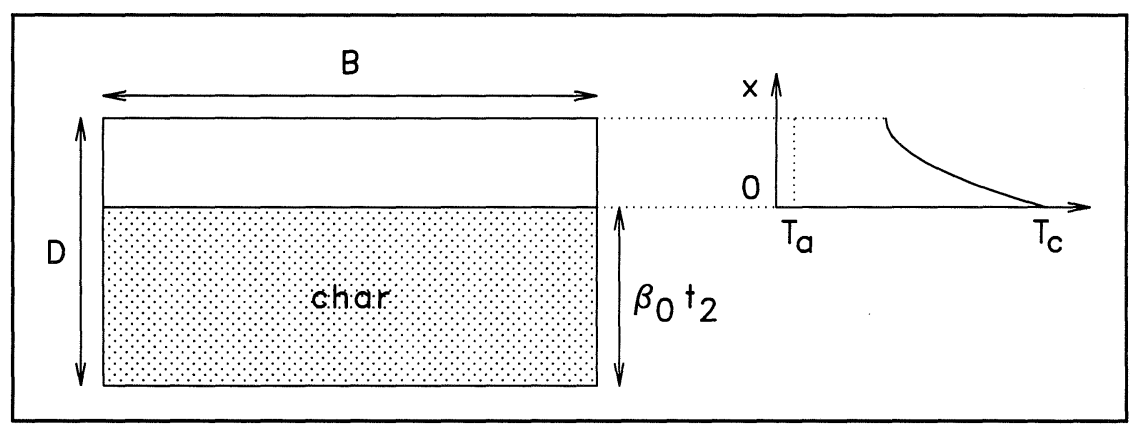

FIGURE 1c. Plank section after $t_{2}$ min of fire exposure $\left(d=D-\beta_{0} t_{2}<40 \mathrm{~mm}\right)$ 
This equation is valid for $t \geq 20 \mathrm{~min}$, and needs to be corrected for shorter exposure times to account for the initial heating and resulting ignition delay and increased rate of charring during the first 10-15 min following ignition. However, because structural failure times of less than $20 \mathrm{~min}$ are of little or no interest, no such correction is generally performed. The remaining section is subdivided into a number of horizontal slices with equal thickness $d_{\mathrm{i}} \approx 1.6 \mathrm{~mm}$. The temperature of each slice is determined from Equations (4) or (5) as a function of the distance between the char front and the center of the slice. The width of each slice is adjusted according to

$$
b_{i}=\frac{E\left(T_{i}\right)}{E\left(T_{a}\right)} B
$$

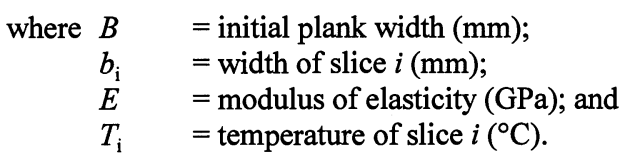

The effect of temperature on the modulus of elasticity is estimated on the basis of recommendations in the literature [12], and is shown in Figure 2. Differences in $E$ between the tension and compression zones are ignored. Figure 3 shows an example of a transformed section that is determined as outlined above. Before calculating the section modulus of the transformed section, it is verified whether the stress in the bottom slice exceeds the ultimate tensile strength adjusted for temperature. If it does, the bottom slice is assigned zero strength, and the verification is performed for the next slice inward. This process is repeated until only one slice is left, or until the slice does not fail. In the first case, the estimated failure time is obviously too high and is used as the upper limit of the solution interval for the next iteration. In the second case, the section modulus of the transformed section is calculated to determine which side of Equation (2) is the largest. If the LHS is larger, the estimated failure time provides a better value for the lower limit of the solution interval. If the LHS is smaller, it is a better value for the upper limit. A better estimate of the failure time is obtained as the midpoint of the new solution interval. This procedure is repeated until Equation (2) is fulfilled within a specified tolerance.

To obtain a design method for decks similar to the equations that are used in the U.S. for beams and columns, Equation (2) was solved for a range of load ratios and plank thicknesses. For this purpose, conservative values were assumed for $\beta_{0}(0.8 \mathrm{~mm} / \mathrm{min})$ and $k_{\mathrm{b}}(0.4)$. The results of the calculations are shown by the data points in Figure 4 . The estimated failure times can be approximated as a linear function of plank thickness:

$$
t_{s f}=C_{1} D-C_{0}
$$




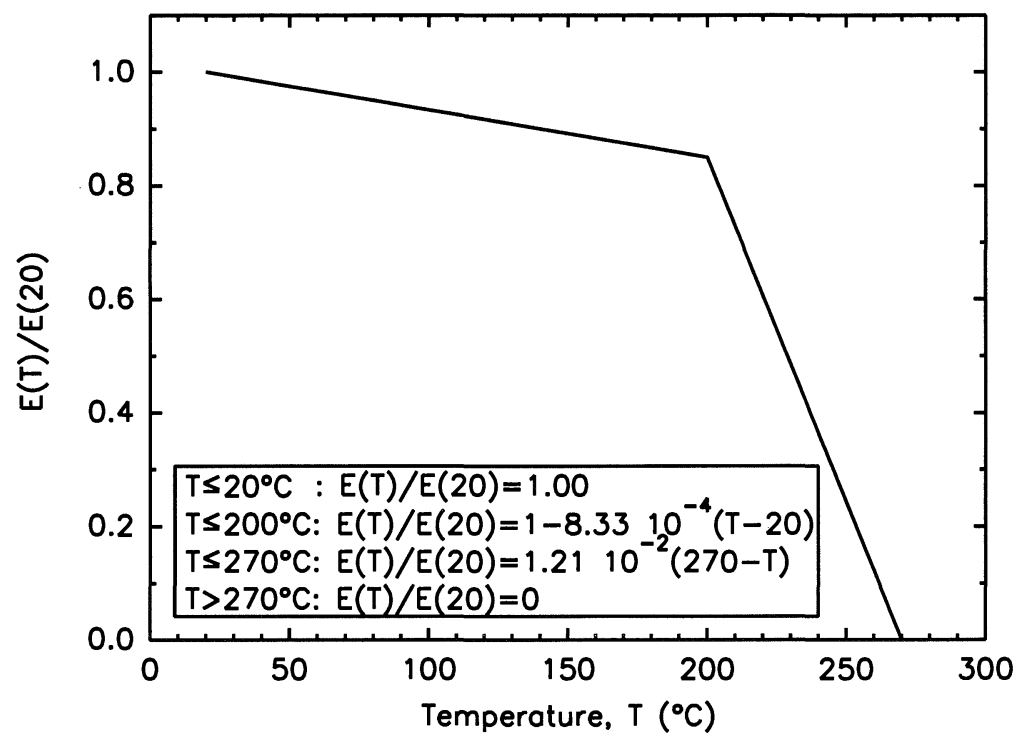

FIGURE 2. Relative reduction of $\mathrm{MOE}$ as a function of temperature

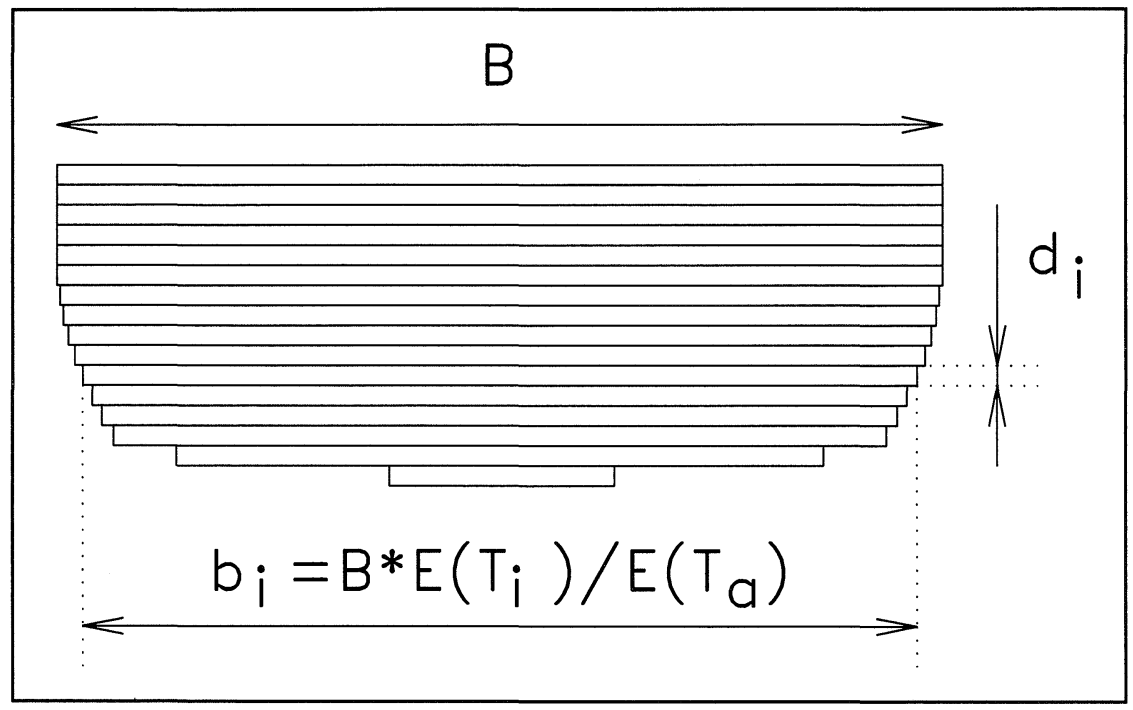

FIGURE 3. Transformation of remaining section 
where $C_{1}$ varies with $R$, and $C_{0}$ is nearly constant. The effective cross-section method in Part 1.2 of Eurocode 5 [5] can be used to obtain a functional relationship between $C_{1}$ and $R$, as described below.

The effective cross-section method accounts for the strength and stiffness reduction over the heated zone below the char layer by increasing the char depth so that

$$
d=D-\beta_{0} t-\delta
$$

where the recommended value for $\delta$ is $7 \mathrm{~mm}$. The remaining section is then assumed to have the initial strength and stiffness. Equation (2), using the effective cross-section method with unspecified $\delta$, can be written as

$$
\frac{B d^{2}}{B D^{2}}=\left[\frac{D-\beta_{0} t-\delta}{D}\right]^{2}=R k_{b}
$$

This quadratic equation can be solved for $t$, leading to

$$
t=\frac{D}{\beta_{0}}\left(1-\sqrt{R k_{b}}\right)-\frac{\delta}{\beta_{0}}
$$

Finally, according to Equations (8) and (11), $C_{1}$ and $C_{0}$ can be expressed as

$$
C_{1}=\frac{1-\sqrt{R k_{b}}}{\beta_{0}} \text { and } C_{0}=\frac{\delta}{\beta_{0}}
$$

A linear fit according to Equation (8) through the data points that result from the transformed section analysis with $\beta_{0}=0.8 \mathrm{~mm} / \mathrm{min}$ and $k_{\mathrm{b}}=0.4$ for $R$ between 0.05 and 1.00 , give $C_{0}$ values ranging from 9.2 to $11.3 \mathrm{~min}$. The highest value of $C_{0}$ is the most conservative, and corresponds to $\delta=9 \mathrm{~mm}$ for $\beta_{0}=0.8 \mathrm{~mm} / \mathrm{min}$. Therefore, the following equation can be recommended for general design purposes

$$
t_{s f}=1.25 D(1-\sqrt{0.4 R})-11.3
$$

The dotted lines in Figure 4 are predictions according to Equation (13). The lines are slightly below some of the calculated data points, indicating that the recommended simplified calculation method is generally slightly conservative compared with the detailed calculations. 


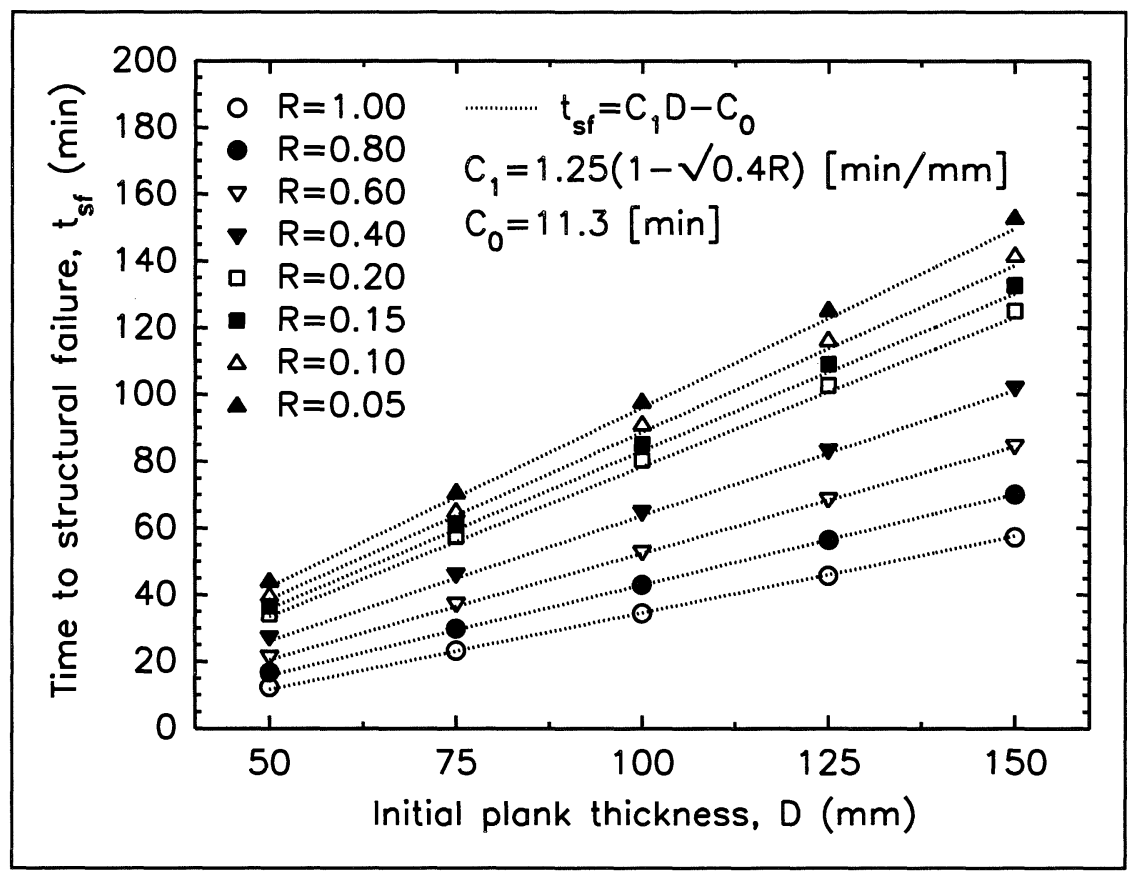

FIGURE 4. Structural fire resistance of exposed timber decks

\section{COMPARISON WITH EXPERIMENTAL DATA}

In 1964, Underwriters' Laboratories (UL) conducted a series of four tests on roof constructions for the Douglas Fir Plywood Association [13]. Two of the tests, referred to as \#2 and \#4, were on exposed timber decks consisting of $140 \mathrm{~mm} \times 38 \mathrm{~mm}$ single tongue-and-groove Douglas fir planks. The decks were loaded to $46 \%$ and $59 \%$ of the design load for tests $\# 2$ and \#4 respectively. The reported thermal penetration time was identical for the two tests at $20 \mathrm{~min}$. Equation (1), with $\xi=0.4, D=38 \mathrm{~mm}$, and $\beta_{0}=0.8 \mathrm{~mm} / \mathrm{min}$ yields $19 \mathrm{~min}$. First structural failure of a plank is not specifically mentioned in the report. However, for test \#2 it is mentioned that deflection was noticeable ( $>32.5 \mathrm{~mm}$ at the center of the deck) at 13 minutes after the start of the test, and that the unsupported ends of some planks started to warp at 24 minutes. Equation (13) gives a value for $t_{\mathrm{sf}}=16 \mathrm{~min}$, which is between the two reported times. For test \#4, the observed times were $11 \mathrm{~min}$ and $18 \mathrm{~min}$ respectively, with $t_{\mathrm{sf}}=13 \mathrm{~min}$ according to Equation (13). The experimental data obtained at UL and calculated results are summarized in Table 2. 
TABLE 2. Experimental data obtained at UL and calculated results

\begin{tabular}{ccccccc}
\hline \multirow{2}{*}{ Test \# } & \multicolumn{2}{c}{ Thermal Separation } & & \multicolumn{2}{c}{ Structural Performance } \\
\cline { 2 - 3 } \cline { 5 - 6 } & $\begin{array}{c}\text { Observed } t_{\mathrm{tf}} \\
(\min )\end{array}$ & $\begin{array}{c}\text { Calculated } t_{\mathrm{tf}} \\
(\min )\end{array}$ & & $\begin{array}{c}\text { Observed } t_{\mathrm{sf}} \\
(\min )\end{array}$ & $\begin{array}{c}\text { Calculated } t_{\mathrm{sf}} \\
(\min )\end{array}$ \\
\hline 2 & 20 & 19 & & $13 . .24$ & 16 \\
4 & 20 & 19 & & $11 . .18$ & 13 \\
\hline
\end{tabular}

In 1969, the American Iron and Steel Institute conducted a comprehensive experimental program at Ohio State University (OSU) [14]. The program included six tests on exposed Douglas fir floor decks. The first two decks, referred to as HT1 and HT2, consisted of $38 \mathrm{~mm}$ x $89 \mathrm{~mm}$ members on edge and covered with $19 \mathrm{~mm}$ wood flooring. Time to thermal failure at the joints was not reported, but time to flamethrough is a reasonable estimate of the end of thermal separation. Flamethrough for the two tests was reported at 61 and $69 \mathrm{~min}$ respectively. Equation (1), with $\xi=0.4, D=108 \mathrm{~mm}$, and $\beta_{0}=0.8 \mathrm{~mm} / \mathrm{min}$ yields $54 \mathrm{~min}$. Although there were no tongues (or splines) and grooves, $\xi=0.4$ is appropriate because the flooring served a similar function as tongues (or splines) and grooves in preventing premature flow of hot gases and products of combustion through the joints. The first two decks were loaded at $31 \%$ of the design load, and structural failure was reported at $62 \mathrm{~min}$ and $56 \mathrm{~min}$ for HT1 and HT2 respectively. Equation (13) gives a value for $t_{\mathrm{sf}}=61 \mathrm{~min}$, which is between the two reported times. The remaining four decks, referred to as HT3 through HT6, consisted of $140 \mathrm{~mm}$ x $64 \mathrm{~mm}$ planks, covered with $19 \mathrm{~mm}$ wood flooring. Flamethrough for the four tests was reported at 54, 31, 35, and $49 \mathrm{~min}$ respectively. Equation (1), with $\xi=0.4, D=83 \mathrm{~mm}$, and $\beta_{0}=0.8 \mathrm{~mm} / \mathrm{min}$ yields 41 min, which is equal to the average of the flamethrough times for all four tests. The HT3 and HT4 decks were loaded at $22 \%$ of the design load, and structural failure was reported at $54 \mathrm{~min}$ for HT3 (and not reported for HT4). Equation (13) gives a value for $t_{\mathrm{sf}}=45 \mathrm{~min}$, which is significantly below the reported time. The HT5 and HT6 decks were loaded at $50 \%$ of the design load, and structural failure was reported at $45 \mathrm{~min}$ for HT6 (and not reported for HT5). Equation (13) gives a value for $t_{\mathrm{sf}}=33 \mathrm{~min}$, which again is significantly below the reported time. Note that the fuel supply to the burners instead of the temperature-time curve in the furnace was controlled during the even-numbered tests. This resulted in slightly more severe exposure conditions than in the odd-numbered tests, which were conducted strictly according to ASTM E 119. The experimental data obtained at OSU and calculated results are given in Table 3.

\section{CONCLUSIONS}

A simple calculation method was developed to estimate the times to thermal and structural failure of timber decks exposed to standard ASTM E 119 fire conditions. The method is in reasonable agreement with experimental data obtained in the U.S. Because the method is generally conservative, it is suitable in its present form to be used for design purposes. 
TABLE 3. Experimental data obtained at OSU and calculated results

\begin{tabular}{cccccc}
\hline \multirow{2}{*}{ Test \# } & \multicolumn{2}{c}{ Thermal Separation } & & \multicolumn{2}{c}{ Structural Performance } \\
\cline { 2 - 3 } \cline { 5 - 6 } & $\begin{array}{c}\text { Observed } t_{\text {tf }} \\
(\text { min })\end{array}$ & $\begin{array}{c}\text { Calculated } t_{\text {tf }} \\
(\text { min) }\end{array}$ & & $\begin{array}{c}\text { Observed } t_{\text {sf }} \\
(\text { min })\end{array}$ & $\begin{array}{c}\text { Calculated } t_{\text {sf }} \\
(\text { min) }\end{array}$ \\
\hline HT1 & 61 & 54 & & 62 & 61 \\
HT2 & 69 & 54 & & 56 & 61 \\
HT3 & 54 & 41 & & 54 & 45 \\
HT4 & 31 & 41 & & Not Reported & 45 \\
HT5 & 35 & 41 & & Not Reported & 33 \\
HT6 & 49 & 41 & & 45 & 33 \\
\hline
\end{tabular}

\section{REFERENCES}

[1] "ASTM E 119 - 88: Standard Test Methods for Fire Tests of Building Construction and Materials," in ASTM Test Standards, pp. 674-694, ASTM, Philadelphia, PA, 1993.

[2] "ISO 834: Fire-Resistance Tests - Elements of Building Construction," International Organization for Standardization, Geneva, Switzerland, 1975.

[3] Lie, T.T., "A Method for Assessing the Fire Resistance of Laminated Timber Beams and Columns", Canadian Journal of Civil Engineering, 4:161-169, 1977.

[4] "Design of One-Hour Fire-Resistive Exposed Wood Members," National Evaluation Board Report No. NRB-250, Council of American Building Officials, Country Club Hills, IL, 1984.

[5] "ENV 1995-1-2:1994: Eurocode 5: Design of Timber Structures - Part 1.2: General Rules - Structural Fire Design," European Commission for Standardization (CEN), Brussels, Belgium, 1994.

[6] "Plank and Beam Framing for Residential Buildings," National Forest Products Association, Washington, DC, 1989.

[7] "ASTM D 245 - 93: Standard Practice for Establishing Structural Grades and Related Properties for Visually Graded Lumber," ASTM, Philadelphia, PA, 1993.

[8] "1991 NDS ${ }^{\circledR}$ - National Design Specification ${ }^{\circledR}$ for Wood Construction," American Forest \& Paper Association, American Wood Council, Washington, DC, 1991.

[9] Hibbeler, J., "Mechanics of Materials," pp. 281-287, McMillan, New York, NY, 1991.

[10] "Eurocode 5: Design of Timber Structures - Part 1.2: General Rules - Structural Fire Design," Final Draft, CEN, Brussels, Belgium, 1993.

[11] Janssens, M., and White, R., "Communication: Temperature Profiles in Wood Members Exposed to Fire," Journal of Fire and Materials, 18:263-265, 1994.

[12] "Structural Fire Protection: Manual of Practice," T.T. Lie ed., p. 43, American Society of Civil Engineers, New York, NY, 1993.

[13] "Fire Resistance of Heavy Timber and Plywood Roof Constructions," Underwriters' Laboratories File NC495, Chicago, IL, 1964.

[14] Bletzacker, R., Lane, W., and Denning, D., "Fire Resistance of Construction Assemblies - Volume I," Ohio State University, Columbus, OH, 1969. 